\title{
Acrylamide: Dermal Exposure Produces Genetic Damage in Male Mouse Germ Cells ${ }^{1}$
}

\author{
Gustavo A. Gutierrez-EsPeleta, ${ }^{*}, 2$ LORI A. Hughes, ${ }^{*}$ Walter W. Piegorsch, $\dagger$ \\ MichaEl D. SHELBY, $\dagger$ AND WALDERICO M. GENEROSO*,3 \\ * Biology Division, Oak Ridge National Laboratory, P.O. Box 2009, Oak Ridge. Tennessee 37738-8077; and † National Institute \\ of Environmental Health Sciences Building, P.O. Box 12233, Research Triangle Park, North Carolina 27709
}

Received December 11, 1990; accepted August 7, 1991

Acrylamide: Dermal Exposure Produces Genetic Damage in Male Mouse Germ Cells. Gutierrez-Espeleta, G. A., Hughes, L. A., Piegorsch, W. W., Shelby, M. D., and GeNeroso, W, M. (1992). Fundam. Appl. Toxicol. 18, 189-192.

Acrylamide is used extensively in sewage and wastewater treatment plants, in the paper and pulp industry, in treatment of potable water, and in research laboratories for chromatography, electrophoresis, and electron microscopy. Dermal contact is a major route of human exposure. It has been shown that acrylamide is highly effective in breaking chromosomes of germ cells of male mice and rats when administered intraperitoneally or orally, resulting both in the early death of conceptuses and in the transmission of reciprocal translocations to live-born progeny. It is now reported that acrylamide is absorbed through the skin of male mice, reaches the germ cells, and induces chromosomal damage. The magnitude of genetic damage appears to be proportional to the dose administered topically. (c) 1992 Society of Toxicology.

The skin does not serve as an effective barrier to all noxious chemicals. There are many cases in laboratory animals and in humans where chemicals were taken up through the skin and distributed throughout the body, giving rise to toxic effects in various organs and tissues (see various reviews in Marzulli and Maibach, 1987). Additionally, dermal exposures of pregnant females to certain chemicals are known to cause embryotoxicity and congenital malformations in laboratory animals, and in some cases, similar effects are suspected in humans (Barlow, 1987). The possibility that the genetic integrity of the germ cells may be affected by mutagens absorbed through the skin has received little attention, even though dermal exposure is a common route of human

\footnotetext{
'This paper has been authored by a contractor of the U.S. Government under Contract DE-AC05-84OR21400. The U.S. Government's right to retain a nonexclusive, royalty-free license in and to the copyright covering this paper, for governmental purposes, is acknowledged.

2 Permanent Address: Escuela de Biologia, Universidad de Costa Rica, San Jose, Costa Rica.

${ }^{3}$ To whom correspondence should be addressed.
}

chemical exposure. A search of the literature turned up only one article (Brusick et al., 1982) reporting a germ cell mutagenicity test using skin painting as the exposure route. In this one case, a hair dye ingredient gave negative results in a mouse dominant lethal test.

Our interest in conducting germ cell mutagenicity tests with acrylamide applied to the skin arose from (a) earlier studies which showed acrylamide to be an effective inducer of chromosomal damage in male mice following intraperitoneal injections (Shelby et al., 1986, 1987) and in male rats following long-term oral administration (Smith et al., 1986), (b) the demonstration that acrylamide applied topically to mice was rapidly absorbed and distributed, binding to macromolecules in a variety of organs including testicular DNA (Carlson and Weaver, 1985), and (c) the fact that skin contact is a common route of human exposure to acrylamide. Reported here are the results of dominant lethal studies in mice demonstrating, for the first time, the accessibility and genetic vulnerability of mammalian germ cells to a chemical mutagen absorbed through the skin.

\section{METHODS}

Dominant lethal experiments were conducted on 10- to 12-week-old male $(\mathrm{C} 3 \mathrm{H} / \mathrm{R} 1 \times 101 / \mathrm{R} 1) \mathrm{F}_{1}$ and female $(\mathrm{C} 3 \mathrm{H} / \mathrm{R} 1 \times \mathrm{C} 57 \mathrm{~B} 1) \mathrm{F}_{1}$ mice. All mice were bred and raised at the Oak Ridge National Laboratory, Biology Division. Mammalian Genetics and Development Section Research Animal Facility. They were caged in plastic boxes with kiln-dried pine shavings, fed Purina Lab Chow, and watered ad libitum. They were housed under daily 9-hr light (7:30 AM to 4:30 PM) and 15-hr dark periods.

Acrylamide ( $\geqslant 99 \%$ purity) was obtained from Sigma Chemical Company, St. Louis, Missouri. The malcs wcre prepared for dermal application by shaving their backs with a small-animal fine clipper. They received the acrylamide treatment once a day for 5 consecutive days. The acrylamide solution was applied to the lumbar region (backs of mice over abdomen) with a micropipett. A $30 \mathrm{~g}$ mouse received $100 \mu \mathrm{l}$ of the solution, which spread over an area of approximately $5.4 \mathrm{~cm}^{2}$. Smaller mice received lesser volumes that were proportional to their weights. Each mouse was placed individually in a 4000-ml glass beaker after each dermal application for about $15 \mathrm{~min}$ to allow the back to dry. Prior to conducting the dominant lethal study, an acute toxicity experiment in which mice were observed for 30 days following the last day of treatment was conducted to determine the maximum tolerated dose under this condition. Doses of 200,150 , and $100 \mathrm{mg} / \mathrm{kg} /$ day were given 
to 8 mice each and the numbers of survivors were 4,7 , and 8 , respectively. Accordingly, the $125 \mathrm{mg} / \mathrm{kg} /$ day dose was chosen as the highest dose to use in the dominant lethal study.

For the dominant lethal study, groups of 30 males were exposed to 125 , $100,75,50$, or $25 \mathrm{mg} / \mathrm{kg} /$ day for 5 consecutive days. The dosing solutions were not analyzed for accuracy of the respective concentrations. Twentyfour males in each control group received the same volume of the carrier solution, which was $70 \%$ methanol, $30 \%$ water. Mice at the highest dose were used in the preliminary experiment. They were given the treatment beginning one day after shaving and they were returned to their cages immediately after the solution dried. Because of the positive effects observed at this dose, it was decided to modify the procedure for the main experiment to (a) ensure that the small skin abrasions caused by the clipper had healed prior to treatment and (b) minimize the possibility of oral ingestion of acrylamide through licking of one's or of each other's back. Thus, treatment in the other dose groups started 4 days after shaving and, after the topically applied solutions had dried, they were restrained individually in tight plastic cubicles (originally designed to restrain mice during exposure to ionizing radiations) for at least $4 \mathrm{hr}$ and then their backs washed in tap water with the aid of a soft brush before being caged together. No irritation of the skin was noticable in all treated groups at the end of the treatment period.

Males were placed with untreated females from Days 7 through 10 following the last exposure. This post-treatment interval was chosen on the basis of the study done earlier in this laboratory which showed that early spermatozoa and late spermatids, but not other stages, are the stages sensitive to induction of dominant lethal mutations with acrylamide (Shelby et al., 1986). Females were examined each morning for the presence of vaginal plugs, which indicated that mating had occurred. Mated females were separated from males immediately after finding a vaginal plug and uterine analyses were carried out 12-14 days after observation of the vaginal plug. Data were obtained on the numbers of total implantations and living and dead implants.

Data were pooled into two post-treatment mating intervals, 7-8 and 910 days. Tests for significance between experimental and control groups were performed on percentage dead implants, average number of living implants per pregnant female, and proportions of females with one or more dead implants. When appropriate, one-sided comparisons were made to identify specific directional departures from the no-effect hypothesis. For percentage dead implants, concern for overdispersion due to per-litter variability precluded the use of simple analysis based on the binomial distribution (Haseman and Soares, 1976). Therefore, a nonparametric form of statistical bootstrapping in which the original data were resampled 4000 times via computer simulations was employed (Efron and Gong, 1983). The resulting bootstrap resamples were then used to estimate the standard errors of the observed percentages. Pairwise comparisons between any two percentages were assessed by a $t$ statistic (Gladen, 1979), corrected for possible heterogeneity in the estimated standard errors using a Satterthwaite adjustment to the $t$ statistic's degrees of freedom (Steel and Torrie, 1980, Chap. 5). The average number of living implants per pregnant female was also analyzed by calculating standard errors from bootstrap resamples. Pairwise comparisons were based on differences in mean responses. Mean dose response was estimated via a linear least-squares model (Steel and Torrie, 1980, Chap. 10 ), with standard errors again calculated from the bootstrap resamples. To assess possible nonlinear departure from this linear model, a lack-of-fit statistic (Draper and Smith, 1981) was calculated, wherein departure from the linear model is evidenced for large values of the statistic. The empirical probability of observing a departure as great or greater than that actually observed for each data set was also calculated from the bootstrap resamples. For proportion of females with one or more dead implants, one-sided pairwise comparisons were assessed by the statistic $Z=\sqrt{X^{2}}$ from the associated $2 \times 2$ table (Steel and Torrie, 1980, Chap. 22).

\section{RESULTS}

Results of uterine analysis of mated females are shown in Table 1. The incidence of dead implants and the proportion of pregnant females with one or more dead implants are significantly higher in each treated group than in the corresponding control group. Reductions in the number of living embryos were significant at all doses, except at the lowest $(25 \mathrm{mg} / \mathrm{kg}$ ). The effects of acrylamide on the numbers of living and dead embryos were generally higher at the matings at 7-8 days than the matings at 9-10 days.

As a single descriptive measure of overall dominant lethal effects, the average number of living embryos per female is the most useful response variable. It reflects both pre- and postimplantation losses due to induced dominant lethality. However, in making comparisons it is necessary to take into account matings in which all of the conceptuses died prior to implantation, as in the case at the highest dose, where a reduced proportion of mated females had implants. Thus, the dose-response analysis was based on live and dead implants at the four lower doses at which the proportions of mated females with implants were apparently not affected by the treatments. The shape of the dose-effect curves for mean number of living embryos and percentage dead implants appear to be complementary for the two post-treatment mating periods (Fig. 1). Tests for lack of linear fit indicate that the dose-response curves for the mean number of living embryos do not deviate significantly from linearity (bootstrap $p=0.082$ and 0.236 for intervals $7-8$ and $9-10$ days, respectively). It should be noted, however, that there is some overlap of confidence limits (Fig. 1) among but not between the three lowest and two highest treatment groups.

\section{DISCUSSION}

Dominant lethal mutations are genetic changes in parental germ cells that lead to death of first-generation carriers. In mice, death generally occurs at around the time of implantation, which is manifested in the uterus in the form of a resorption body. In severe cases, lethal mutations may be expressed in early cleavage stages whereupon the embryo is lost prior to implantation. The minimum conditions for a positive dominant lethal effect set by the International Commission for Protection against Environmental Mutagens and Carcinogens (1983) are a significant reduction in the average number of living embryos and a significant increase in either the average number of dead implantations or the number of females with one or more dead implants. All treatment groups met this condition with the exception of $25 \mathrm{mg} / \mathrm{kg} /$ day (lowest dose used), at which no significant changes were induced in the mean number of living embryos per female. The lack of significance in this endpoint could be attributed to the small numbers of pregnancies analyzed. The significant trend in the dose response and the consistency in the control values for both the incidence of dead implants and the number of females with one or more dead implants suggest an effect at the $25 \mathrm{mg} / \mathrm{kg} /$ day exposure. In contrast, none of the doses used show signs of neurotoxicity. 
Thus, the results are consistent with a model whereby acrylamide was absorbed through the skin, and reached and affected early spermatozoa in epididymis and late spermatids in seminiferous tubules, causing dominant lethal mutations. Dominant lethal mutations induced by acrylamide, which are presumed to be caused by chromosome breakage effects (Shelby et al., 1986), have been found to be associated with the production of heritable translocations (Shelby et al., 1987). The dose of $75 \mathrm{mg} / \mathrm{kg} /$ day in the present study induced $70 \%$ dominant lethal mutations. From the earlier study in this laboratory (Shelby et al., 1987), this level of dominant lethal mutations induced by intraperitoneal injections of 40 $\mathrm{mg} / \mathrm{kg} \times 5$ acrylamide is associated with $24 \%$ carriers of balanced reciprocal translocations among live progeny. Whether the shape of the dose-response curve for acrylamide-induced heritable translocations is similar to that for dominant lethals remains to be determined. A dose-effect study for intraperitoneally injected acrylamide has not been done. Therefore, while it appears that intraperitoneal injection produced higher dominant lethal responses than dermal application, the magnitude of the difference and whether the difference is dose dependent are not known.

Laboratory investigators and municipal sewer grout workers (McHugh, 1987) are, in particular, exposed to acrylamide primarily by the dermal route. In mice, acrylamide is readily absorbed through the skin and binds to DNA in the testes (Carlson and Weaver, 1985). The linear or close-

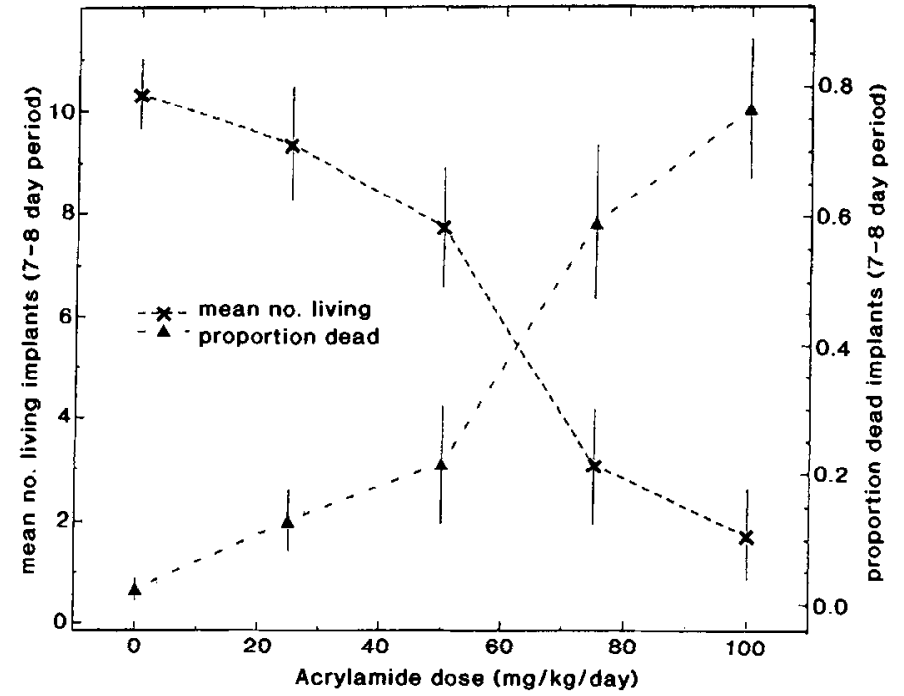

FIG. 1. Male mouse dominant lethal responses to acrylamide administered topically. Mice were treated once a day for 5 consecutive days. Vertical bars represent $95 \%$ confidence intervals on mean or percentage response.

to-linear dose response implies that genetic damage may be produced at exposure levels much lower than the lowest dose used in the present study, perhaps even down to the levels that humans encounter in the workplace. This possibility needs to be resolved through a combined dominant lethal

TABLE 1

Summary Data from Dominant Lethal Studies in Male Mice Topically Exposed to Acrylamide

\begin{tabular}{|c|c|c|c|c|c|c|c|c|}
\hline $\begin{array}{c}\text { Treatment } \\
(\mathrm{mg} / \mathrm{kg} / \text { day })^{a}\end{array}$ & $\begin{array}{l}\text { Mating period } \\
\text { (days) }^{b}\end{array}$ & $\begin{array}{l}\text { Number of } \\
\text { mated } \\
\text { females }\end{array}$ & $\begin{array}{l}\text { Number of } \\
\text { pregnant } \\
\text { females }\end{array}$ & $\begin{array}{c}\text { Number of } \\
\text { implantations } \\
\text { per pregnant } \\
\text { female }\end{array}$ & $\begin{array}{l}\text { Number of } \\
\text { pregnant females } \\
\text { with } \geq 1 \text { dead } \\
\text { implant }\end{array}$ & $\begin{array}{l}\text { Number of } \\
\text { living embryos } \\
\text { per pregnant } \\
\text { female }\end{array}$ & $\begin{array}{l}\text { Dead } \\
\text { implants } \\
(\%)\end{array}$ & $\begin{array}{c}\text { Dominant } \\
\text { lethals }^{c} \\
(\%)\end{array}$ \\
\hline \multirow[t]{2}{*}{ Control $^{d}$} & 7,8 & 37 & 36 & 10.6 & 9 & 10.3 & 2.6 & \\
\hline & 9,10 & 47 & 42 & 10.0 & 11 & 9.6 & 3.6 & \\
\hline \multirow[t]{2}{*}{25} & 7,8 & 21 & 19 & 10.8 & $16^{e}$ & 9.4 & $13.2^{e}$ & 10 \\
\hline & 9,10 & 20 & 17 & 10.5 & $13^{e}$ & 9.5 & $9.0^{f}$ & -8 \\
\hline \multirow[t]{2}{*}{50} & 7,8 & 21 & 20 & 9.9 & $18^{e}$ & $7.8^{f}$ & $21.7^{e}$ & 25 \\
\hline & 9,10 & 28 & 23 & 10.4 & $22^{e}$ & $8.4^{g}$ & $18.8^{e}$ & 4 \\
\hline \multirow[t]{2}{*}{75} & 7,8 & 24 & 21 & 7.5 & $21^{e}$ & $3.1^{e}$ & $59.2^{e}$ & 70 \\
\hline & 9,10 & 41 & 36 & 9.4 & $30^{e}$ & $6.3^{e}$ & $32.9^{e}$ & 38 \\
\hline \multirow[t]{2}{*}{100} & 7,8 & 18 & 17 & 7.3 & $17^{e}$ & $1.7^{e}$ & $76.6^{\circ}$ & 83 \\
\hline & 9,10 & 34 & 25 & 9.0 & $23^{e}$ & $5.0^{e}$ & $45.1^{e}$ & 49 \\
\hline \multirow[t]{2}{*}{ Control } & 7,8 & 10 & 9 & 11.1 & 3 & 10.7 & 4.0 & \\
\hline & 9,10 & 10 & 10 & 9.7 & 1 & 9.6 & 1.0 & \\
\hline \multirow[t]{2}{*}{125} & 7,8 & 17 & 9 & 5.4 & $9^{h}$ & $1.0^{h}$ & $81.6^{h}$ & 91 \\
\hline & 9,10 & 26 & 18 & 7.2 & $18^{n}$ & $2.2^{h}$ & $70.0^{h}$ & 77 \\
\hline
\end{tabular}

\footnotetext{
${ }^{a}$ Once a day for 5 consecutive days.

${ }^{b}$ After the last dose.

${ }^{c}$ Dominant lethals $(\%)=[1-$ average number of living embryos (Treated)/average number of living embryos $($ Control) $] \times 100$

${ }^{d}$ Data were pooled from two control groups.

$e_{1}, f_{g} p<0.001,0.01$, and 0.05 , respectively (after bootstrap comparison with pooled controls, unadjusted for multiple comparisons).

${ }^{h} p \leq 0.001$ (after hontstrap comparison with concomitant control).
} 
and heritable translocation study at low exposure levels addressing all conditions of exposure that are relevant to evaluation of risk. There arc two obvious questions: (1) Is mouse skin similar to human skin with respect to acrylamide absorption? (2) Do mice and humans metabolize/excrete acrylamide in the same fashion?

\section{ACKNOWLEDGMENTS}

Research was jointly sponsored by the Office of Health and Environmental Research, U.S. Department of Energy, under contract DE-AC05-84OR21400 with Martin Marietta Energy Systems, Inc., and by the National Institute of Environmental Health Sciences under IAG Y01-ES-20085. We thank Dr. Jack B. Bishop, Dr. Mary Esther Gaulden, Dr. Joseph K. Haseman, Dr. Jerrold S. Heindel, and Dr. Gary A. Sega for their critical review of the manuscript.

\section{REFERENCES}

Barlow, S. M. (1987). Reproductive hazards from chemicals absorbed through the skin. In Dermatotoxicology (F. N. Marzulli and H. I. Maibach, Eds.), pp. 597-605. Hemisphere, Washington, DC.

Brusick, D. J., Jagannath, D. R., and Matheson, D. (1982). The activity of 2-(2', $4^{\prime}$-diaminophenoxy)ethanol in 3 genetic toxicity bioassays. Mutat. Res. 102, 361-372.

Carlson, G. P., and Weaver, P. M. (1985). Distribution and binding of $\left[{ }^{14} \mathrm{C}\right]$ acrylamide to macromolecules in SENCAR and BALB/C mice following oral and topical administration. Toxicol. Appl. Pharmacol. 79, 307-313.
Draper, N., and Smith, H. (1981). Applied Regression Analysis, 2nd ed., Chap. 1. Wiley, New York.

Efron, B., and Gong, G. (1983). A leisurely look at the bootstrap, the jackknife, and cross-validation. Am. Stat. 37, 36-48.

Gladen, B. (1979). The use of the jackknife to estimate proportions from toxicological data in the presence of litter effects. J. Am. Statist. Assoc. 74, 278-282.

Haseman, J. K., and Soares, E. R. (1976). The distribution of fetal death in control mice and its implications on statistical tests for dominant lethal effects. Mutat. Res. 41, 277-288.

International Commission for Protection against Environmental Mutagens and Carcinogens (1983). Committee Final Report. Mutat. Res. 114, 117 177.

Marzulli, F. N., and Maibach, H. I. (1987). Dermatotoxicology, 3rd ed. Hemisphere, New York.

McHugh, J. M. (1987). Assessment of Airborne Exposure and Dermal Contact to Acrylamide During Chemical Grouting Operations. U.S. Environmental Protection Agency Publ. 560/5-87-009.

Shelby, M. D., Cain, K. T., Cornett, C. V., and Generoso, W. M. (1987). Acrylamide: Induction of heritable translocations in male mice. Environ. Mutagen. 9, 363-368.

Shelby, M. D., Cain, K. T., Hughes, L. A., Braden, P. W., and Generoso, W. M. (1986). Dominant lethal effects of acrylamide in male mice. Mutat. Res. 173, 35-40.

Smith, M. K., Zenick, H., Preston, R. J., George, E. L., and Long, R. E. (1986). Dominant lethal effects of subchronic acrylamide administration in the male Long-Evans rat. Mutat. Res. 173, 273-277.

Steel, R. G. D., and Torrie, J. H. (1980). Principles and Procedures of Statistics. A Biometric Approach. 2nd ed. McGraw-Hill, New York. 